\title{
Using the Schema Owned in Solving Problems through Assimilation and Accommodation
}

\author{
Mubarik \\ Postgraduate Program of Mathematics Education, UniversitasNegeri Surabaya, Surabaya, Indonesia \\ barik4691@gmail.com \\ Mega Teguh Budiarto, Raden Sulaiman \\ Department of Mathematics, UniversitasNegeri Surabaya, Surabaya, Indonesia
}

\begin{abstract}
Schema has an important role in problem solving process because it determines an action towards problem solving. Problem solving involves two aspects namely the problem to be solved and the knowledge (schema) that is owned. This study was aimed at describing the use of owned schema in problem solving through assimilation and accommodation. The research subjects were students who had studied geometry. Data were collected through the provision of schema identification test, problem solving test, and interviews to two subjects. Based on the results and data analysis, it can be concluded that there were two cases of the use of schema in problem solving through assimilation and accommodation. They were: 1) the use of inappropriate and irreversible schema. In this case, the problem solving done by the subject was dominated by the assimilation process, and 2) the use of unsuitable and alterable schema. In this case, the subject did assimilation in problem solving. However, the subject realized that the inappropriate schema had been used in problem solving. So, the subject did the accommodation and could use the appropriate schema in problem solving.
\end{abstract}

Keywords-Scheme; Problem Solving; Assimilation; Accommodation.

\section{INTRODUCTION}

Schema has a very important role to help someone in problem solving. The schema will provide an overview of matters related to the problems that are faced. Schema is the mental structure of organized information [1]. In addition, [2] explains a schema is an organized mind act that is used repeatedly in order to respond to the environment. When receiving information, the information received will be responded based on the existing schema. Schema theory states that when we reconstruct information, we match it to the information already in our minds [3]. Suppose a person has studied the relationship between angles, if two parallel lines are cut off by another line, then a schema of corresponding angles relationship will be formed. This schema will be used when dealing with problems or obtaining information related to the schema. The construction of the subject conceived as a structured set of schemes was closely united with the construction of the real as a coordinated set of defined attributes [4].

Schema is formed through the learning experience and problem solving that have been done. The schema is organized in the brain and interconnected between one another. When facing problems or obtaining new information, the brain will match new information or problems encountered with a schema already owned. When, matching is done so the brain can respond to new problems or information received. According to [5], schema (plural: schemata) is potential to act in a certain way". The more schemas a person has, the easier it will be to respond to the information or problems encountered. The matching occurs through assimilation and accommodation. A scheme, according to Piaget, is a set of the organism's reactions that are not necessarily observable, and that are tightly connected in a totality or whole. Activation of a scheme is possible in diverse situations ("assimilation" of reality by a scheme), but modification or differentiation ("accommodation") is also possible [6]

In learning there will always be an interaction between the knowledge already owned with the information obtained through assimilation and accommodation [7]. There are two possible conditions that occur in the interaction. First, knowledge owned is in accordance with the information obtained. Second, knowledge owned does not match the information received. When the knowledge owned is in accordance with the information received, the information will be incorporated into the existing schema. Based on the existing schema, someone will respond to new information. This is a process of assimilation [8, 9, 10].

Assimilation is the mechanism by which the subject applies its existing schemas of reality in an effort to appropriate and incorporate new elements of its environment [11]. Assimilation is a cognitive process that takes place when individuals use their existing schemas to make sense of the events in the world, involving trying to relate something new to something that we already know [1]. Similar opinion is assimilation involves the interpretation of events in terms of existing cognitive structure [12]. Someone will use the existing knowledge (schema) in interpreting the events or information obtained.

New information is not always in accordance with the schema that we have. If new information always matches the existing schema, actually there is no new information or knowledge that we obtain. When the knowledge owned does not match the information received, the existing knowledge (schema) will be modified to fit the information received. This is an accommodation process [8, 10, 13, 14].

According to Zhang [15], accommodation refers to the process by which the subject adjusts the old schema or builds a 
new schema on the basis of the old one in order to accept and accommodate the new object when it fails to conform to the subject's schema. Castillo, Heredia, and Gallardo [16] explain that accommodation involves changing mindsets to adapt to reality built with newly acquired information. Veg [11] explains that accommodation involves altering existing schemas, or ideas, as a result of new information or new experiences. When the new object resists, the mechanism of accommodation intervenes to bring about a change in the structure and allow the incorporation of new elements. According to Woolfolk [17], accommodation is altering existing schemes or creating new ones in response to new information. Accommodation occurs when a person must change existing schemes to respond to a new situation. Accommodation changes existing schemas or creates new ones in response to new information. Accommodation occurs when a person has to change the existing schema to respond to the information as it is not suitable with the new information.

The interaction between knowledge owned and the information received leads to assimilation and accommodation so that assimilation and accommodation become an important matter in learning activities and problem solving. Ormrod [2] suggests that children learn through two complementary processes namely assimilation and accommodation. This is in accordance with Piaget's opinion that cognitive learning and development occur as a result of two complementary processes namely assimilation and accommodation.

Having a schema is not enough to be able to solve the problem. It needs the ability to use the right schema in problem solving. In addition, the ability to change the schema used in problem solving is also needed so that problem solving can work. If someone has an ability to change the schema used in problem solving, then when someone makes a mistake in using the schema, someone can change the schema used so that problem solving can work.

\section{RESEARCH METHOD}

This study used qualitative method to describe the use of schema that had been owned in problem solving through the process of assimilation and accommodation. Research subjects were students who had studied geometry. Data were collected through initial schema test, problem-solving test, and interview to two students each having initials DL and MN. The subjects did the initial schema test. It was to ensure that the subjects had schema related to the later problem solving test. Interviews were conducted to ensure that the answers of problem solving tests written down by the subjects were an overview of the use of the schema already in solving the problem through assimilation and accommodation processes. The subject is said to assimilate if it can reveal the suitability between the schemes owned and new information obtained. In addition, if the subject can reveal discrepancies between the schemes owned and new information obtained and can reveal/show changes in the scheme that is owned the subject is said to do accommodation.

\section{RESULTS AND DISCUSSION}

Schema identification test (SIT) was given as follows.

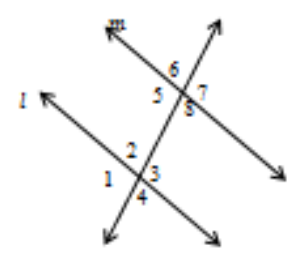

SIT aimed to determine whether the subject had a schema of corresponding angles relationships if two parallel lines were cut off by another line. Furthermore, subjects were given a problem solving test below:

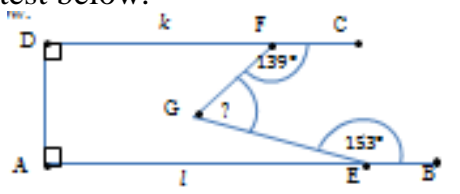

a. What is the position of line $\mathrm{k}$ to line?

b. Determine $\mathrm{m} \angle \mathrm{FGE}$ !

Based on the results and data analysis, it could be concluded that there were 2 cases of schema use in problem solving through assimilation and accommodation: 1) the use of inappropriate and irreversible schema. In this case, the problem solving done by the subject was dominated by the assimilation process, and 2) the use of inappropriate and alterable scheme. In this case, the subject did assimilation in problem solving. However, the subject was aware of the inappropriateness schema used in problem solving, so the subject did accommodation and could use the appropriate schema in problem solving.

\section{A. The use of inappropriate and irreversible schema}

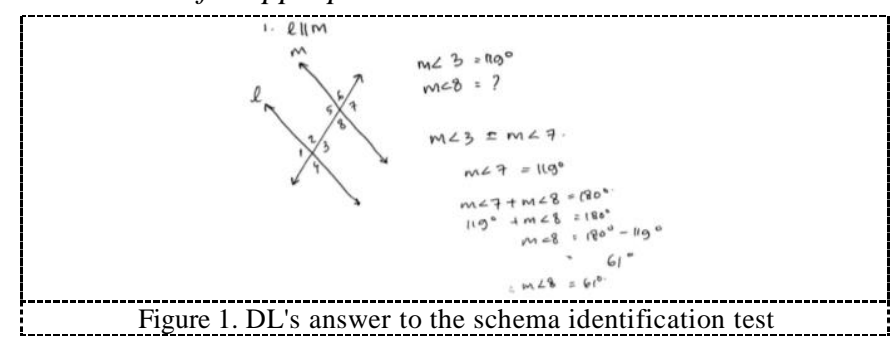

Figure 1 shows that Subject DL had a schema about the relationship between angles if two parallel lines were cut off by another line namely the relationship between two corresponding angles. In addition, subject also had a schema on the relationship between supplementary angles. With the existing schema, subject could determine the exact size of the angle being asked. DL knew that the corresponding angle had the same size, so DL concluded $\angle 3=\angle 7$. Next DL used a schema of the supplementary angle. DL knew that $\angle 8$ was supplemented with $\angle 7$ and the number of two angles supplementing each other was $180^{\circ}$. With such schema subject could determine $\mathrm{m} \angle 8$.

Problem encountered was a problem related to the relationship between angles if two parallel lines were cut off by another line. DL's answer to the given problem is presented in Figure 2 below.

Given $1 \| m$, if $m \angle 3=119^{\circ}$ then determine $m \angle 8$ ! 


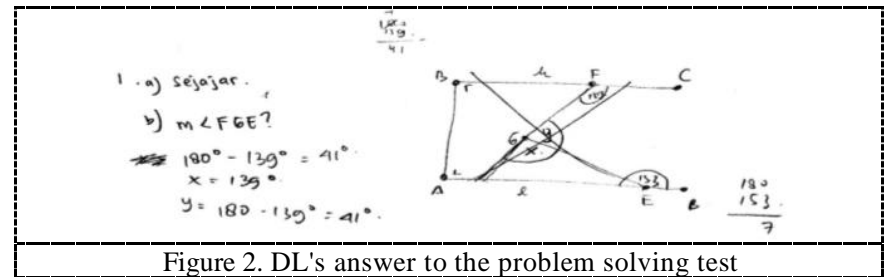

In solving the problem, DL started by extending $\overline{F G}$ so as to cut $\overline{A B}$ in $\mathrm{P}$. Next, DL gave $\angle \mathrm{EGP}$ as $\mathrm{x}$ and $\angle \mathrm{FGE}$ as $\mathrm{y}$. Based on the schema identification test, it was known that subject already had a schema about corresponding angles. The information obtained in the direct problem was assimilated into the existing schema. $\angle \mathrm{CFG}$ and $\angle \mathrm{EGP}$ were assimilated into a corresponding angles schema. Thus, DL concluded $m \angle \mathrm{CFG}=m \angle \mathrm{EGP}$. Then DL assimilated the information of supplementary angles in the problem that was encountered into the schema that the subject had. DL concluded $\angle \mathrm{FGE}$ and $\angle$ EGP were supplemented, so DL obtained $\mathrm{y}=180^{\circ}-139^{\circ}=$ $41^{\circ}$.

In solving the problem, DL already had a schema about corresponding angles, but DL could not use the schema correctly. After looking back at the answer he wrote, DL realized the mistake he made so that DL tried to change the answer given by changing the schema used. DL tried to extend $\overline{E G}$, so he cut $\overline{D C}$. However, the subject could not find the answer by using the schema.

The process of problem solving done by DL was dominated by the assimilation process. DL directly assimilated the information in the problems encountered into the existing schema. In solving the problem, DL realized the schema used was not appropriate, but DL could not change the schema he used, so the answer given was not correct. According to [10], assimilation and accommodation is an important process in determining the success of problem solving. According to Veg [11], if we merely highlight the importance of assimilation, we will never be able to know new things because assimilation relates only to what individuals already know. However, with the accommodation process completed then problem solving can be successful. This suggests assimilation and accommodation is an important and complementary process of successful problem solving.

\section{B. Matching test on logistic parametric model}

\begin{aligned} &$M \angle 8=180^{\circ}-m L 3$ (dalam sepihak) \\ &$\Leftrightarrow \Rightarrow 80^{\circ}-11^{\circ} \\ & M L 8=61^{\circ} \\ &$\hline Figure 3. MN's answer to the schema identification test \end{aligned}

MN had a schema about the relationship between angles if two parallel lines were cut off by another line. MN used a unilateral interior angle schema to determine the magnitude of the angle being asked (Figure 3 ). In solving the problem, MN tried to use the schema of the angles number of triangle that was $180^{\circ}$. Thus, $\mathrm{MN}$ connected the points of $\mathrm{F}$ and $\mathrm{E}$ to form EFG triangle (Figure 4). However, MN could not solve the problem using the schema.

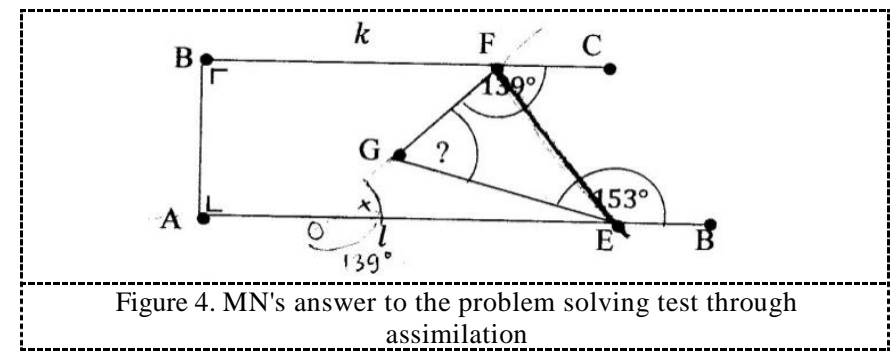

MN realized that the schema used was not appropriate, so $\mathrm{MN}$ changed the schema used in solving the problem (Figure $5)$.

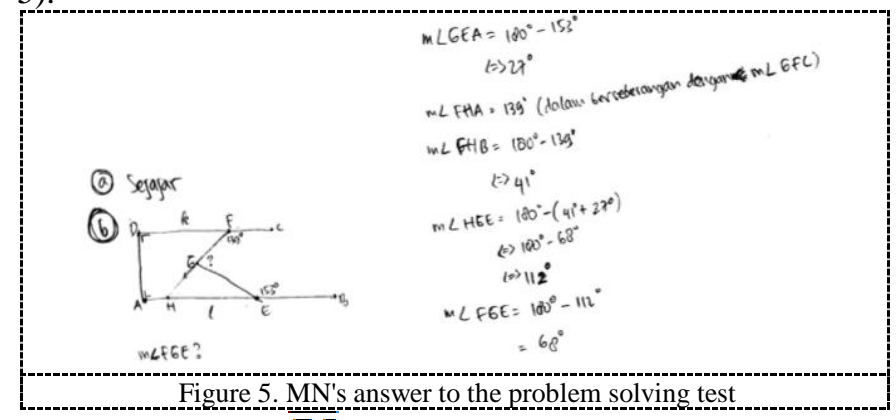

MN extended $\overline{F G}$ thereby it cut $l$ in $\mathrm{H}$. MN used a supplementary angle schema so as to obtain $m \angle \mathrm{GEA}=180^{\circ}$ $153^{\circ}=27^{\circ}$. MN also used an alternate interior angle, $\angle \mathrm{FHA}=$ $139^{\circ}$ for it was alternate interior with $\angle$ GFC. Furthermore, in determining $m \angle \mathrm{FHB}, \mathrm{MN}$ used a supplementary angle schema, so $m \angle \mathrm{FHB}=41^{\circ}$. MN also used a triangle-angle number schema equal to $180^{\circ}$. Thus, $\mathrm{MN}$ got $m \angle \mathrm{HE}=180^{\circ}$ $68^{\circ}=112^{\circ}$. In determining $m \angle \mathrm{FGE}$ subject used the owned schema about the supplementary angle. $\angle \mathrm{FGE}$ was supplemented with $\angle E G H$, where the number of angles supplemented each other was $180^{\circ}$. Thus, MN got $m \angle \mathrm{FGE}=$ $180^{\circ}-112^{\circ}=68^{\circ}$.

In problem solving, $\mathrm{MN}$ assimilated the information gained from the problem given to the owned schema. However, the schema used by MN was not appropriate, so MN could not solve the existing problem. Recognizing the inappropriateness of the schema used, MN did accommodation. MN changed the schema used in solving the problem. By changing the schema used, MN could solve the problem. Besides the assimilation process, $\mathrm{MN}$ also performed accommodation process in problem solving so that the problem solving could succeed. According to [18], assimilation and accommodation is an important process in determining the success of problem solving. According to [19], if we merely highlight the importance of assimilation, we will never be able to know new things because assimilation relates only to what individuals already know. However, with the accommodation process completed then problem solving can be successful. This suggests assimilation and accommodation is an important and complementary process of successful problem solving.

\section{CONCLUSION}

Having a schema that suits the problem faced is not enough to determine the success of problem solving. It requires 
conformity or appropriateness in using the schema owned through assimilation and accommodation to help the success of problem solving. In problem solving, there are two cases of schema use through assimilation and accommodation: 1) the use of inappropriate and irreversible schema, and 2) the use of inappropriate and alterable schema.

\section{REFERENCES}

[1] R. Moreno, Educational Psychology. New York: Jhon Wiley \& Sons, Inc., 2010.

[2] J. E. Ormrod, Psikologi pendidikan. Jakarta: Erlangga, 2008.

[3] J. W. Santrock, Life-Span Development. Jakarta: Erlangga, 2012.

[4] P. Barrouillet, "Theories of cognitive development: from piaget to today”, Developmental Review, vol. 38, pp. 1-12, 2015.

[5] B. R. Hergenhahn \& M. H. Olson, Theories of learning. Jakarta: Prenada Media, 2017.

[6] S. Morra, C. Gobbo, Z. Marini, \& R. Sheese, Cognitive Development Neo-Piagetian Perspectives. New York: Taylor \& Francis Group, 2008.

[7] H. B. Bormanaki \& Y. Khoshhal, "The role of equilibration in piaget's theory of cognitive development and its implication for receptive skills: a theoretical study", Journal of Language Teaching and Research, vol. 8(5), pp. 996-1005, 2017.

[8] B. Blake \& T. Pope, "Developmental psychology: Incorporating Piaget's and Vygotsky's Theories in Classrooms", 2008.

[9] R. E. Slavin, Educational Psychology Theory And Practice 8th ed. United States Of America: Pearson education Inc., 2006.

[10] E. A. Di Paolo, X. E. Barandiaran, M. Beaton, \& T. Buhrmann, "Learning to Perceive in the Sensorimotor Approach: Piaget's Theory of Equilibration Interpreted Dynamically Frontiers", Human Neuroscience, vol. 8(551), 2014.
[11] S. N. Veg, "The use of longitudinal case studies and semiotics for analysing brand development as process of assimilation or accommodation", Qualitative Market Research: An International Journal, vol. 17(4), pp. 373- 392, 2014.

[12] R. Kaasila, E. Pehkonen \& A. Hellinen, "Finnish pre-service teachers' and upper secondary students' understanding of division and reasoning strategies used", Educational Studies in Mathematics, vol. 73(3), pp. 247-261, 2014.

[13] P. Eggen \& D. Kauchak, Educational Psychology Windows On Classrooms 9th ed. United States of America: Pearson Education Inc., 2013.

[14] F. Y. Yu, "Cognitive Conflicts and Resolutions in Online Text Revisions: Three Profiles", Journal of Educational Technology \& Society, vol. 13(4), 2010.

[15] Z. Zhang, "Assimilation, accommodation, and equilibration: A schemabased perspective on translation as process and as product", International Forum of Teaching and Studies, vol. 11(1-2), p. 84, 2015.

[16] M. Castillo, Y. Heredia \& K. Gallardo, "collaborative work competency in online postgraduate students and its prevalence on academic achievement", Turkish Online Journal of Distance Education (TOJDE), vol. 18(3), 2017.

[17] A. Woolfolk, Educational Psychology $9^{\text {th }}$ ed. United States of America: Pearson Education Inc., 2005.

[18] T. H. Cadez \& V. M. Kolar, "Comparison of types of generalizations and problem-solving schemas used to solve a mathematical problem", Journal Educational Studies in Mathematics, vol. 89(2), pp. 283-306, 2015.

[19] P. F. H. Ribeiro, T. Stoltz, D. de Camargo, V. C. L. Blum, J. M. Machado, S. P. de Freitas, C. L. Dias, \& R. T. J. Dos, "Creation Process during Learning of Gifted Students: Contributions from Jean Piaget", Online Submission, vol. 8, pp. 505-513, 2017. 